\title{
The Environmental Flight from Reason
}

\author{
Michael Barker ${ }^{1}$
}

In our current epoch of global collapse -- of both the organic environment and the very socio-economic order that is so intent on consuming the former -- irrationality is a comforting friend for ruling class elites; with the same being true for some of those struggling to live in an era of austerity. With the ever-ready complicity of the mass media, sustainable-sounding means of placating the current crisis are readily seized upon by well-meaning citizens, enabling far-sighted elites to offer yet another green lifeline for capitalism. Unfortunately within this milleaux of faux-solutions, irrational ideas prosper all too readily, undermining the development of a meaningful democratic response to the current crisis. By using the environmental movement as a case study, this paper traces the incubation of this flight from reason over the past century. Particular emphasis will be placed on Soil Association's mystical New Age approach to the promotion of organic agriculture. In this way this paper will demonstrate how influential proponents of various irrationalities have worked closely with many erstwhile environmentalists to encourage the adoption of both arguments and allies that ultimately only serve to sustain agents of capitalism and mysticism, and not the environment that most environmentalists honestly seek to protect. Such a strange amalgam of interests has led to a real concern over the growth of what has been termed eco-fascism: a dangerous trend that can arguably rise to the fore in times of austerity. This study seeks to reclaim green discourses of sustainability for an eco-socialist alternative. [Article copies available for a fee from The Transformative Studies Institute. E-mail address: journal@transformativestudies.org Website: http://www.transformativestudies.org (02015 by The Transformative Studies Institute. All rights reserved.]

KEYWORDS: Organic, Agriculture, Mysticism, Biodynamic, Ecology.

\footnotetext{
${ }^{1}$ Michael Barker is a member of the Socialist Party (England and Wales). He has been writing for alternative media outlets since 2006, and at present is a regular contributor to Swans Commentary. His work has been published by the following media organizations: Ceasefire Magazine, Corporate Watch (UK), Countercurrents, CounterPunch, Dissident Voice, Fifth Estate Online, Green Left Weekly, Jacobin, Media-ocracy, Monthly Review Zine, New Community Quarterly, New Left Project, PULSE Media, Spinwatch, Socialist Project, State of Nature, Upside Down World, Variant, and in the past he was a regular contributor to Znet. Address correspondence to: Michael Barker; e-mail: mbarker@riseup.net.
} 